\title{
The time it takes to switch attention
}

\author{
GORDON D. LOGAN \\ Vanderbilt University, Nashville, Tennessee
}

\begin{abstract}
An experiment is reported that measured the time it takes to switch attention from one set of locations to another in response to a cue that indicates the relevant locations. The experiment compared sequences of trials in which the same locations were cued in succession with sequences in which different locations were cued in succession in order to separate cue-encoding time from attention-switching time. Same-location sequences require cue encoding but not attention switching. They were substantially faster than different-location sequences, which require both cue encoding and attention switching. Formal models were fitted to time-course functions generated by presenting the cues 0,100 , 200,300 , or $400 \mathrm{msec}$ before the target displays. The model fits suggest that cue encoding took 67-74 msec and attention switching took 76-101 msec.
\end{abstract}

The time it takes to switch attention has been measured in many ways, and the measurement is controversial. In visual search experiments, it takes $30-50 \mathrm{msec}$ to reject a distractor (Wolfe, 1998). That interval measures switching time only if distractors are examined serially and individually, which are controversial assumptions (Townsend, 1990; Treisman, 1982). In attentional blink experiments, it takes $500-600 \mathrm{msec}$ to finish processing one target and to begin processing another (Ward, Duncan, \& Shapiro, 1996). That interval confounds switching time with target processing time and masking (Moore, Egeth, Berglan, \& Luck, 1996). This article examines a procedure popularized by Eriksen and colleagues, in which a cue indicates the position of a target in a multielement display (Colegate, Hoffman, \& Eriksen, 1973; Eriksen \& Collins, 1969; Eriksen \& Hoffman, 1972). The interval between the onset of the cue and the onset of the target (stimulus onset asynchrony, or SOA) is manipulated to measure the time-course of switching attention. Performance improves as SOA increases and reaches asymptote at long SOAs. Researchers often interpret the SOA at which performance reaches asymptote as a measure of the time it takes to switch attention (Colegate et al., 1973; Tsal, 1983). Typical values range from 150 to $300 \mathrm{msec}$.

There are two problems with using the asymptotic SOA as an estimate of attention switching time. First, it is difficult to estimate the asymptote without fitting an

This research was supported by National Science Foundation Grants BCS 0133202 and BCS 0218507. The author thanks Julie Delheimer for testing the subjects and analyzing the data and Claus Bundesen for valuable comments about the modeling. Correspondence concerning this article should be addressed to G. D. Logan, Department of Psychology, Vanderbilt University, Nashville, TN 37203 (e-mail: gordon. logan@vanderbilt.edu). explicit function to the curve. The asymptotic SOA is often defined as the point at which differences between successive SOAs first become significant (Tsal, 1983). This is questionable statistically (Sperling \& Weichselgartner, 1995). Second, switching time is probably a random variable, so the asymptotic SOA reflects the upper limit of the distribution of switching times rather than the mean (Sperling \& Weichselgartner, 1995). This article addresses these problems by adapting methods for analyzing time-course functions from Logan and Bundesen (2003). These methods treat the time-course function as the cumulative distribution of finishing times for switching attention, which reflects the probability that the subject has switched attention to the cued location at a given SOA. Explicit functions are fitted to the time-course function and parameters of the functions are interpreted as measures of switching time.

There is another problem: The time-course function reflects the time required to encode the cue as well as the time to switch attention. Cue-encoding time must be a random variable, so the time-course function reflects the probability that the cue was encoded at a given SOA as well as the probability that attention was switched. I address this problem by adapting procedures and models from the explicit task-cuing procedure in the taskswitching literature. In this procedure, a cue indicates which task to perform on a subsequent target. To estimate task-switching time, researchers compare trials on which tasks repeat with trials on which tasks change. Cue encoding occurs whether tasks repeat or change, but task switching occurs only when tasks change. The difference between task-repeat and task-change trials provides a measure of task-switching time that is not confounded with cue-encoding time.

The present experiments separate attention-switching time from cue-encoding time by comparing sequences of 
trials in which the same locations are cued with sequences in which different locations are cued. The analysis assumes that attention stays in the same location from one trial to the next, so same-location trials do not require attention switching but different-location trials do. This assumption may be controversial because many researchers believe attention is mobile, and there may be enough time between trials for several shifts of attention. However, there are theoretical reasons to believe that attention might stay in the same location until it is called elsewhere. Spatial attention appears to share processes with spatial working memory, so attended locations may remain active for several sec (Awh, Jonides, \& ReuterLorenz, 1998; Bundesen, 1990; Cowan, 2001; Pylyshyn, 1989). Ultimately, the validity of the assumption is an empirical question that can be settled by comparing reaction time (RT) on same- and different-location trials.

Attention-switching time can be estimated with models Logan and Bundesen (2003) developed for timecourse functions in the explicit task-cuing procedure. The models assume that cue-encoding time and attentionswitching time are both random variables. Subjects respond quickly when cue encoding and attention switching are complete and slowly when cue encoding and attention switching are not complete. The time-course function traces the probability that these processes are complete at each SOA, reflecting the cumulative distribution functions for cue encoding and attention switching. For simplicity and mathematical tractability, the models assume that cue-encoding time and attentionswitching time are distributed exponentially (see Logan $\&$ Bundesen, 2003). Model fits to time-course functions yield estimates of the means of these distributions.

The simplest model is Logan and Bundesen's (2003) Model 1. It assumes that subjects begin each trial by encoding the cue. If the current cue is the same as the last cue, there is no need to switch attention. The focus of attention remains where it was on the last trial. RT reflects cue-encoding time and target-processing time. Thus,

$$
\mathrm{RT}=\mathrm{RT}_{\mathrm{Base}}+\mu_{\mathrm{c}} \exp \left(-\mathrm{SOA} / \mu_{\mathrm{c}}\right),
$$

where $\mathrm{RT}_{\text {Base }}$ is asymptotic $\mathrm{RT}$ and $\mu_{\mathrm{c}}$ is mean cueencoding time. If the current cue is different from the last cue, attention must switch to a new location. Consequently, RT reflects cue-encoding time, attention-switching time, and target-processing time. When the cue changes

$$
\begin{aligned}
\mathrm{RT}= & \mathrm{RT}_{\text {Base }}+\exp \left(-\mathrm{SOA} / \mu_{\mathrm{c}}\right)\left(\mu_{\mathrm{c}}+\mu_{\mathrm{s}}\right) \\
& +\frac{1 / \mu_{\mathrm{c}}}{1 / \mu_{\mathrm{c}}-1 / \mu_{\mathrm{s}}}\left[\exp \left(-\mathrm{SOA} / \mu_{\mathrm{s}}\right)\right. \\
& \left.-\exp \left(-\mathrm{SOA} / \mu_{c}\right)\right] \mu_{\mathrm{s}},
\end{aligned}
$$

where $\mathrm{RT}_{\mathrm{Base}}$ is asymptotic RT, $\mu_{\mathrm{c}}$ is mean cue-encoding time, and $\mu_{\mathrm{s}}$ is mean attention-switching time.

Model 1 assumes cue-processing time is the same whether or not the cue repeats. This assumption has been falsified in task-switching experiments that use two cues for each task (e.g., A and B mean "report color"; C and D mean "report shape"). Trials on which the cue and the task repeat (e.g., $\mathrm{A} \rightarrow \mathrm{A}$ ) are faster than trials on which the cue changes but the task repeats (e.g., B $\rightarrow$ A; Logan \& Bundesen, 2003, 2004; Mayr \& Kliegl, 2003). To separate cue-repetition benefits from task-switching time, Logan and Bundesen (2003) proposed a more complex model, called Model $2+1$, in which cue encoding is faster when the cue repeats than when it changes, but task-switching occurs only if the cue indicates a different task.

The present experiment adapted the two-cue-per-task procedure to attention switching. Two different cues were used for each target location. If the cue repeats from one trial to the next, cue encoding could benefit from repetition but attention would not be switched. According to Model $2+1$, on same-cue trials

$$
\mathrm{RT}=\mathrm{RT}_{\text {Base }}+\mu_{\mathrm{r}} \exp \left(-\mathrm{SOA} / \mu_{\mathrm{r}}\right),
$$

where $\mathrm{RT}_{\mathrm{Base}}$ is asymptotic $\mathrm{RT}$ and $\mu_{\mathrm{r}}$ is mean cueencoding time. When the cue changes but indicates the same location,

$$
\mathrm{RT}=\mathrm{RT}_{\text {Base }}+\mu_{\mathrm{a}} \exp \left(-\mathrm{SOA} / \mu_{\mathrm{a}}\right),
$$

where $\mathrm{RT}_{\mathrm{Base}}$ is asymptotic RT and $\mu_{\mathrm{a}}$ is mean cueencoding time. If there are cue encoding benefits, $\mu_{\mathrm{r}}<$ $\mu_{\mathrm{a}}$. When the cue changes and indicates a different location, the cue must be encoded and attention must be switched. Model $2+1$ predicts that

$$
\begin{aligned}
\mathrm{RT}= & \mathrm{RT}_{\mathrm{Base}}+\exp \left(-\mathrm{SOA} / \mu_{\mathrm{a}}\right)\left(\mu_{\mathrm{a}}+\mu_{\mathrm{s}}\right) \\
& +\frac{1 / \mu_{\mathrm{a}}}{1 / \mu_{\mathrm{a}}-1 / \mu_{\mathrm{s}}}\left[\exp \left(-\mathrm{SOA} / \mu_{s}\right)\right. \\
& \left.-\exp \left(-\mathrm{SOA} / \mu_{\mathrm{a}}\right)\right] \mu_{\mathrm{s}},
\end{aligned}
$$

where $\mathrm{RT}_{\text {Base }}$ is asymptotic $\mathrm{RT}, \mu_{\mathrm{a}}$ is mean cue-encoding time, and $\mu_{\mathrm{s}}$ is mean attention-switching time. Model $2+1$ assumes that $\mu_{\mathrm{a}}$ is the same in Equations 4 and 5 . Model 1 is nested in Model $2+1$ : If $\mu_{\mathrm{r}}=\mu_{\mathrm{a}}$, then Equations 3-5 reduce to Equations 1-2. This nesting makes it possible to test the significance of improvements in goodness of fit from Model 1 to Model $2+1$ to determine the necessity of assuming cue-encoding benefits.

This article measures attention-switching time and separates it from cue-encoding time by fitting Models 1 and $2+1$ to data from experiments in which subjects were cued to attend to locations to search for targets. There were four potential target locations. A charactertarget or distractor-appeared in each location, and two locations were cued on each trial. Targets were vowels and distractors were consonants. Targets occurred in cued locations on half of the trials. Following Eriksen and colleagues, vowels occurred in uncued locations on half of the trials to ensure that subjects processed the cues and attended to cued locations. Ignoring the cues would produce errors on half of the "target absent" trials.

Two versions of the experiment were conducted, differing only in the configuration of the target displays. In the "diamond" version, the configuration was diamond shaped. Targets and distractors appeared directly above 
and below the center of the screen and directly to the right and left of the center of the screen. In the "square" version, the configuration was square shaped. One character appeared in the upper left corner, one in the upper right, one in the lower left, and one in the lower right. With both configurations, subjects were cued to attend to opposite locations (e.g., with diamond displays, they were cued to attend to top and bottom or to left and right locations) to discourage eye movements. Half of the transitions between trials involved attending to the same location, and half involved attending to different locations, following common practice in the explicit taskcuing literature.

The cues were dots placed near the target locations. There were two kinds of cues for each display configuration. One set of cues appeared "outside" the configuration (e.g., above the top character and below the bottom character in diamond displays) and the other set appeared "inside" the configuration (e.g., below the top character and above the bottom character in diamond displays). This produced three transitions between successive trials: same cue, in which the same cue signaled the same locations, same location, in which a different cue signaled the same locations, and other location, in which a different cue signaled the other locations. According to Models 1 and $2+1$, the time-course function on same-cue and same-location trials should reflect cue-encoding time but not attention switching time, and the time-course function on other-location trials should reflect both cueencoding time and attention-switching time.

\section{METHOD}

\section{Subjects}

Two groups of 16 subjects each served in a single session for pay or course credit. One group saw the diamond configuration and the other saw the square configuration.

\section{Apparatus and Stimuli}

The stimuli were displayed on Sony Trinitron monitors controlled by Dell Dimension computers. Responses were collected from the " $z$ " and " $/$ " keys on the computer keyboard. Viewing distance was not constrained, but it was approximately $60 \mathrm{~cm}$. At this distance, $1 \mathrm{~cm}$ is approximately equal to 1 degree of visual angle. There were four displays on each trial. The first was a 500-msec warning display, consisting of an $8 \times 8 \mathrm{~cm}$ white outline box that surrounded the area in which targets, distractors, and cues would appear. The second was a cue display, consisting of two white 1.5$\mathrm{mm}$ dots presented $0.7 \mathrm{~cm}$ inside or $0.7 \mathrm{~cm}$ outside the location the letters would occupy. There were four cues with each display type. For diamond displays, inside cues appeared either below the top letter and above the bottom letter or to the right of the left letter and to the left of the right letter. Outside cues appeared above the top letter and below the bottom letter or left of the left letter and right of the right letter. For square displays, cues appeared on imaginary diagonals extending from the center of the display outward. After an SOA of $0,100,200,300$, or $400 \mathrm{msec}$, the target display appeared. Target displays contained four white $5 \times 8$-mm letters and the two cues from the cue display. Targets were the vowels A, E, I, O, and U. Distractors were the consonants B, C, D, F, and G. The distance between the top and bottom letters in each display was $4.2 \mathrm{~cm}$. The distance between the left and right letters in each display was also
$4.2 \mathrm{~cm}$. The target display was exposed until subjects responded, whereupon it was replaced by a $500-\mathrm{msec}$ blank screen.

\section{Procedure}

A target was presented in one of the cued locations on half of the trials. To ensure that subjects attended to the cued locations, a vowel was presented in one of the uncued locations on half of the targetpresent trials and target-absent trials. Thus, ignoring the cues would produce errors on $50 \%$ of target-absent trials. The targets and distractors presented on each trial were selected at random. Targets occurred equally often in each cued location and in each uncued location. There were two types of cues for each location (inside and outside). Each cue type occurred equally often with each target position. Each cue type and target position occurred equally often at each SOA. There were 960 trials. The order of trials was randomized separately for each subject.

Subjects were allowed breaks every 80 trials. Half of the subjects in each group pressed the $z$ key for "target present" and the / key for "target absent." The other half did the opposite.

\section{RESULTS}

Mean RT and the percentage of correct responses were calculated for each subject for each cell of a 2 (target present or absent) $\times 3$ (cue transition: same cue, same location, other location $) \times 5($ SOA: $0,100,200,300$, $400 \mathrm{msec}$ ) experimental design. Separate $2 \times 3 \times 5$ analyses of variance (ANOVAs) were conducted for RTs and accuracies for each display configuration. Summary tables for the ANOVAs appear in Table 1. Accuracy was high, averaging $96 \%$ with the diamond configuration and $95 \%$ with the square configuration, suggesting that subjects used the cues to direct their attention. The only significant effect in the accuracy ANOVAs was target presence. Accuracy was lower for target-present responses ( $M=95 \%$ for diamond, $93 \%$ for square) than for target-absent responses $(M=98 \%$ for diamond, $97 \%$

Table 1

Summary Tables for ANOVAs Performed on Mean Reaction Times and Percentage of Correct Responses for the Diamond and Square Display Configurations

\begin{tabular}{|c|c|c|c|c|c|}
\hline \multirow[b]{2}{*}{ Effect } & \multicolumn{3}{|c|}{ Reaction Time } & \multicolumn{2}{|c|}{ Percent Correct } \\
\hline & $d f$ & $M S_{\mathrm{e}}$ & $F$ & $M S_{\mathrm{e}}$ & $F$ \\
\hline \multicolumn{6}{|c|}{ Diamond } \\
\hline Target presence $(\mathrm{T})$ & 1,15 & $21,423.61$ & $15.63^{* *}$ & 36.86 & $25.53^{* *}$ \\
\hline Cue transit & 2,30 & $4,511.62$ & $30.53^{* *}$ & 5.02 & 1.00 \\
\hline $\mathrm{SOA}(\mathrm{S})$ & 4,60 & $2,348.04$ & $73.76^{* *}$ & 13.25 & 0.38 \\
\hline $\mathrm{T} \times \mathrm{C}$ & 2,30 & $1,757.31$ & 1.00 & 17.09 & 1.43 \\
\hline $\mathrm{T} \times \mathrm{S}$ & 4,60 & & 0.3 & 17.99 & 1.33 \\
\hline $\mathrm{C} \times \mathrm{S}$ & 8,120 & 2 & $7.27^{* *}$ & 17.10 & 1.98 \\
\hline $\mathrm{T} \times \mathrm{C} \times \mathrm{S}$ & 8,120 & $2,027.03$ & 0.98 & 13.85 & 0.41 \\
\hline \multicolumn{6}{|c|}{ Square } \\
\hline Target presence $(\mathrm{T})$ & 1,15 & $11,760.33$ & $27.14^{* *}$ & 52.25 & $30.53^{* *}$ \\
\hline Cue transition (C) & 2,30 & $3,009.63$ & $21.34^{* *}$ & 18.27 & 0.37 \\
\hline $\mathrm{SOA}(\mathrm{S})$ & 4,60 & $2,364.04$ & $53.80^{* *}$ & 12.71 & 2.49 \\
\hline $\mathrm{T} \times \mathrm{C}$ & 2,30 & $2,750.92$ & 0.17 & 11.45 & 2.17 \\
\hline $\mathrm{T} \times \mathrm{S}$ & 4,60 & $1,560.69$ & 1.10 & 19.06 & 1.39 \\
\hline $\mathrm{C} \times \mathrm{S}$ & 8,120 & $1,819.00$ & $2.80^{* *}$ & 19.41 & 1.24 \\
\hline $\mathrm{T} \times \mathrm{C} \times \mathrm{S}$ & 8,120 & $1,825.26$ & 0.46 & 15.67 & 0.74 \\
\hline
\end{tabular}

Note-SOA, stimulus onset asynchrony. ${ }^{* *} p<.01$. 
for square). This effect did not compromise the effects of cue transition or SOA, so the analyses focus on RT.

\section{Mean RT}

Mean RTs across subjects are presented as points in Figure 1 for the diamond configuration and in Figure 2 for the square configuration. For both configurations, RT was faster for target-present responses ( $M=697 \mathrm{msec}$ for diamond; $706 \mathrm{msec}$ for square) than for target-absent responses $(M=749 \mathrm{msec}$ for diamond; $758 \mathrm{msec}$ for square), and RT decreased as SOA increased. For both configurations, RT was affected by cue transition. Repeating the cue had little effect: Same-cue RTs were 703 and $721 \mathrm{msec}$ for diamond and square, respectively, whereas same-location RTs were 709 and $719 \mathrm{msec}$ for diamond and square, respectively. RT was slower when the cued location changed-other-location RTs were 757 and $755 \mathrm{msec}$ for diamond and square, respectivelysuggesting a substantial cost for shifting attention. The cue transition effect decreased as SOA increased and dis- appeared by the longest SOA. These conclusions were supported by ANOVAs on mean RTs (see Table 1).

\section{Model Fits}

The models were fit to the mean RTs averaged over subjects and to the mean RTs for each subject. The values of the best-fitting parameters and measures of goodness of fit (the correlation, $r$, and the root-mean squared deviation, $R M S D$, between observed and predicted values) are presented in Table 2. The models fit the means across subjects better than individual subjects, but the parameter values for the fits to the means fell within the 95\% confidence intervals of the average parameter values from the fits to individual subjects. Thus, the fits to the means across subjects describe individual subjects well, so I will focus on those fits.

Model 1 was fit to mean RTs using the Solver routine in Microsoft Excel to minimize RMSD. Equation 1 was fit to the same-cue and same-location conditions, and Equation 2 was fit to the other-location condition. Equa-

Diamond: Target Present

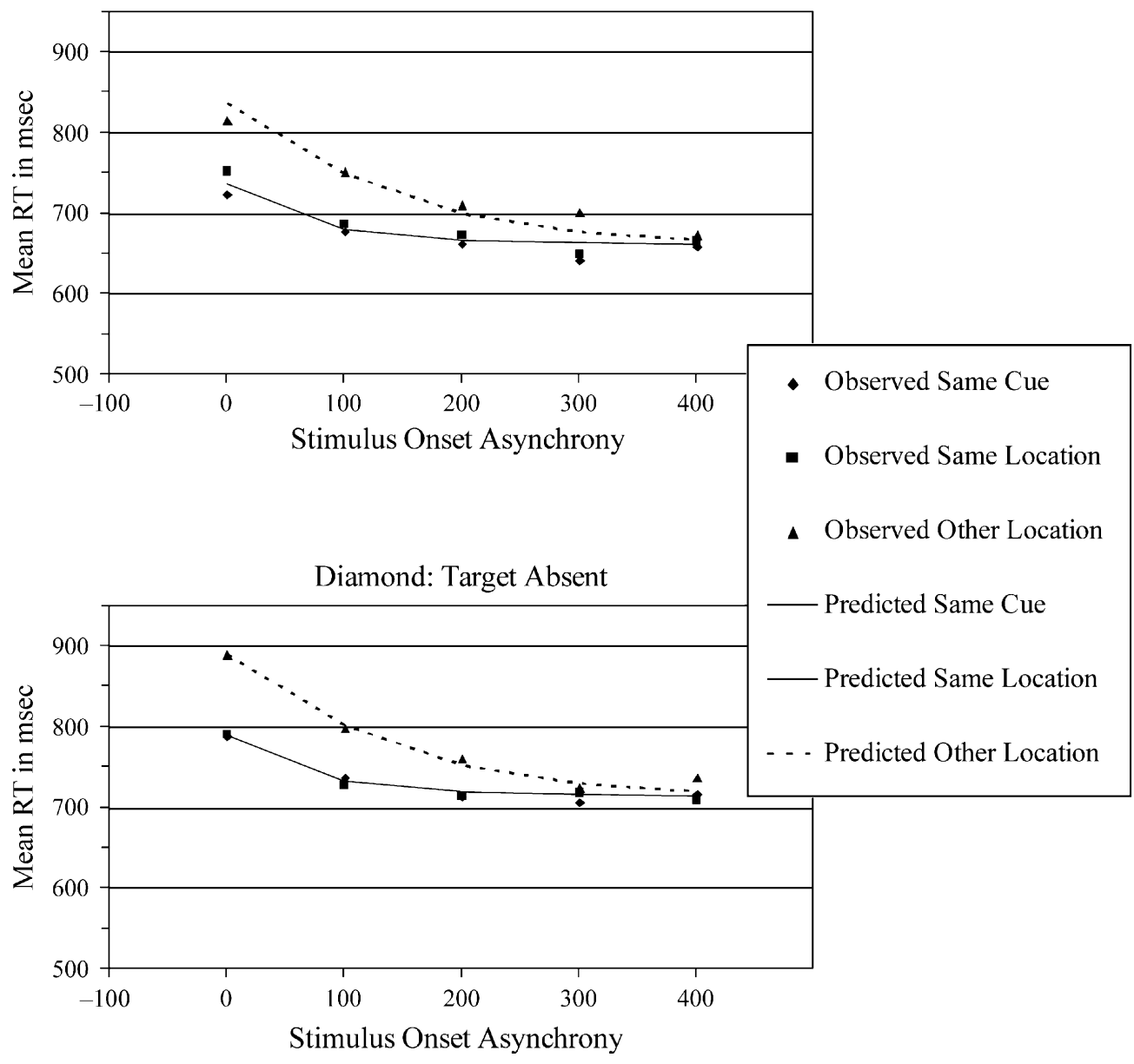

Figure 1. Mean reaction time as a function of the stimulus onset asynchrony between the cue and the target display for the diamond display configuration. The top panel contains reaction times for target-present responses. The bottom panel contains reaction times for target-absent responses. The points represent the observed data. The lines represent the theoretical predictions from Model 1. 
Square: Target Present

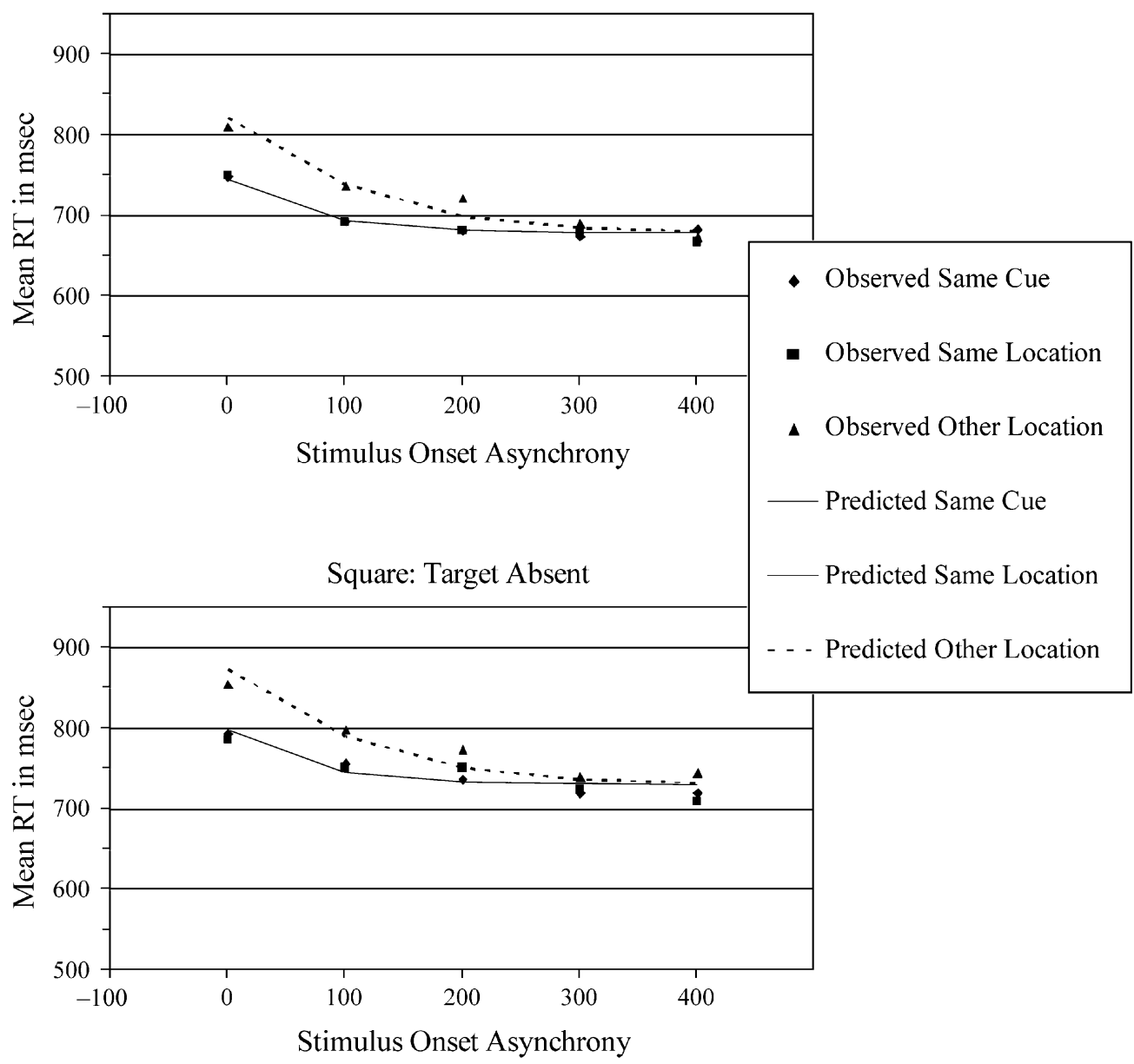

Figure 2. Mean reaction time as a function of the stimulus onset asynchrony between the cue and the target display for the square display configuration. The top panel shows reaction times for target-present responses. The bottom panel shows reaction times for target-absent responses. The points represent the observed data. The lines represent the theoretical predictions from Model 1.

tions 1 and 2 were fit simultaneously to the 30 means in the diamond condition and then to the 30 means in the square condition. Four parameters were estimated for each display configuration: $\mathrm{RT}_{\text {Base-Present }}$ for target-present responses, $\mathrm{RT}_{\text {Base-Absent }}$ for target-absent responses, and common values of cue-encoding time $\left(\mu_{\mathrm{c}}\right)$ and attentionswitching time $\left(\mu_{\mathrm{s}}\right)$ for target-present and target-absent responses. The predicted values from the fits to means across subjects are plotted as lines in Figures 1 and 2.

Model 1 fit the data quite well for both display configurations. Fisher's least significant difference (LSD) test was used to calculate $95 \%$ confidence intervals for the mean RTs, using the error term for the interaction between target presence, cue transition, and SOA. LSD was $32 \mathrm{msec}$ for diamond displays and $30 \mathrm{msec}$ for square displays. No predicted value fell outside these $95 \%$ confidence intervals.

Model 2+1 was fit to the mean RTs using the same procedure as the Model 1 fits. Equation 3 was fit to the same-cue condition, Equation 4 to the same-location condition, and Equation 5 to the other-location condition. Five parameters were estimated for each display configuration: $\mathrm{RT}_{\text {Base-Present }}$ for target-present responses, $\mathrm{RT}_{\text {Base-Absent }}$ for target-absent responses, cue-encoding time on same-cue trials $\left(\mu_{\mathrm{r}}\right)$, cue-encoding time on samelocation and other location trials $\left(\mu_{\mathrm{a}}\right)$, and attentionswitching time $\left(\mu_{\mathrm{s}}\right)$. Model $2+1$ fit the data well, but no better than Model 1. The significance of the improvement in goodness of fit over Model 1 was tested by comparing the correlations between observed and predicted values. The improvement was not significant for diamond $[F(1,25)=1.62]$, or square displays $[F(1,25)<$ $1.0]$, indicating there was no significant cue-encoding benefit with either configuration.

\section{DISCUSSION}

The results with both display configurations showed typical time-course functions. RT decreased and approached asymptote as SOA increased. The novel empir- 
Table 2

Values of the Best-Fitting Parameters and Measures of Goodness of Fit of Models 1 and $2+1$ to the Mean Reaction Times (in Milliseconds) Over Subjects and to Mean Reaction Times for Individual Subjects from the Diamond and Square Display Configuration Conditions

Diamond Configuration

\begin{tabular}{lcccccc} 
& \multicolumn{7}{c}{ Model 1 } \\
\cline { 2 - 7 } & $\mathrm{RT}_{\text {Base-Present }}$ & $\mathrm{RT}_{\text {Base-Absent }}$ & $\mu_{\mathrm{c}}$ & $\mu_{\mathrm{s}}$ & $r$ & $R M S D$ \\
\hline Mean over subjects & 661 & 714 & 74 & 101 & .983 & 10 \\
Average individual & 658 & 711 & 76 & 102 & .852 & 36 \\
Standard error & 20 & 22 & 9 & 12 & .014 & 3
\end{tabular}

Model $2+1$

\begin{tabular}{lccccccr}
\cline { 2 - 7 } & $\mathrm{RT}_{\text {Base-Present }}$ & $\mathrm{RT}_{\text {Base-Absent }}$ & $\mu_{\mathrm{r}}$ & $\mu_{\mathrm{a}}$ & $\mu_{\mathrm{s}}$ & $r$ & $R M S D$ \\
\hline Mean over subjects & 662 & 714 & 69 & 80 & 96 & .984 & 10 \\
Average individual & 657 & 709 & 75 & 82 & 97 & .859 & 36 \\
Standard error & 20 & 22 & 9 & 10 & 12 & .014 & 3
\end{tabular}

Square Configuration

Model 1

\begin{tabular}{lcccccc}
\cline { 2 - 6 } & $\mathrm{RT}_{\text {Base-Present }}$ & $\mathrm{RT}_{\text {Base-Absent }}$ & $\mu_{\mathrm{c}}$ & $\mu_{\mathrm{s}}$ & $r$ & $R M S D$ \\
\hline Mean over subjects & 679 & 730 & 67 & 76 & .975 & 10 \\
Average individual & 674 & 726 & 73 & 73 & .780 & 38 \\
Standard error & 21 & 21 & 8 & 12 & .026 & 3
\end{tabular}

Model 2+1

\begin{tabular}{lccccccc} 
& $\mathrm{RT}_{\text {Base-Present }}$ & $\mathrm{RT}_{\text {Base-Absent }}$ & $\mu_{\mathrm{r}}$ & $\mu_{\mathrm{a}}$ & $\mu_{\mathrm{s}}$ & $r$ & $R M S D$ \\
\hline Mean over subjects & 679 & 731 & 69 & 65 & 78 & .975 & 10 \\
Average individual & 674 & 725 & 76 & 69 & 78 & .791 & 37 \\
Standard error & 21 & 21 & 10 & 10 & 11 & .025 & 3 \\
\hline
\end{tabular}

$\overline{\text { Note}}-r=$ correlation between observed and predicted values; $R M S D=$ root-mean squared deviations between observed and predicted values. Mean over subjects = values from model fits to data averaged over subjects. Average individual = average values from fits to individual subjects. Standard error = standard error of average values from fits to individual subjects (i.e., standard error of Average individual).

ical contribution was to separate cue-encoding time from attention-switching time by distinguishing between cue transitions. Same-cue and same-location transitions did not differ from each other, suggesting there was no benefit from repeating a cue (cf. Logan \& Bundesen, 2003, 2004; Mayr \& Kliegl, 2003). Both were faster than otherlocation transitions, indicating a cost for switching attention separate from the cost of cue encoding. This cost is consistent with the assumption, borrowed from the task-switching literature, that attention remained focused on the locations from the last trial unless it was called elsewhere, and it justifies the modeling of the time-course functions. ${ }^{1}$

The model fits allowed estimates of the time it takes to switch attention. The $\mu_{\mathrm{s}}$ parameters for the Model 1 fits in Table 2 suggest that it took $101 \mathrm{msec}$ to switch attention with the diamond displays and $76 \mathrm{msec}$ to switch attention with the square displays. The difference approached significance in the fits to the individual subject data $[t(30)=1.70, p=.10]$. I have no explanation for this difference. Both values are substantially shorter than the SOA at which the other-location time-course function reached asymptote, suggesting that the asymptotic SOA overestimates the time it takes to switch attention (also see Sperling \& Weichselgartner, 1995).
The model fits also allowed estimates of the time it takes to encode the cue. The $\mu_{\mathrm{c}}$ parameters from Model 1 fits in Table 2 suggest that it took $74 \mathrm{msec}$ with the diamond display and $67 \mathrm{msec}$ with the square display. Cue encoding contributed about as much to the time-course function as attention switching. This finding challenges the standard interpretation of the time-course function as a measure of the time it takes to switch attention (Colegate et al., 1973; Eriksen \& Hoffman, 1972; Tsal, 1983). It underscores the importance of using procedures and models in which cue-encoding time and attention-switching time can be separated (Logan \& Bundesen, 2003). The modeling analysis shows that attention-switching time cannot be estimated simply by subtracting RT in the same-cue or same-location condition from RT in the other-location condition: Subtracting Equation 1 from Equation 2 does not remove cue-encoding time from the other-location time-course function.

The model fits assumed that subjects paid attention to two locations simultaneously and switched attention from one set of two locations to another in a single act of control. Although there is evidence that people can attend to two locations simultaneously (Awh \& Pashler, 2000; Kramer \& Hahn, 1995), it is important to consider what would happen if only one location was attended at 
a time. I constructed a serial version of Model 1 and fitted it to the data. The fits were as good as the fits of the parallel model and the switching time parameters were essentially the same. This followed because the extra attention switches in the serial model occurred after the target appeared (after the SOA) and so affected only $\mathrm{RT}_{\text {Base }}$. During the SOA, there was one attention switch on otherlocation trials and no attention switch on same-cue and same-location trials, just as in the parallel model. Target-absent trials required one attention switch after the target display appeared-to examine the second letterand target-present trials required a switch on half of the trials. Thus, the difference between target-present and target-absent RTs represents half of an attention switch and half of the time required to decide a letter was a consonant.

Should the cuing procedure be the preferred method for estimating attention-switching time? Each method has advantages and disadvantages. Visual search is plagued by mimicry problems. The attentional blink procedure needs to be modeled formally to separate attention switching from target processing and masking (but see Sperling \& Weichselgartner, 1995). The cuing method requires assumptions about how cues are processed and the controversial assumption that attention stays in the same location from one trial to the next. Ideally, different methods should be integrated into a general theory of attention, like Bundesen's (1990) theory of visual attention or recent extensions of it (Logan, 2002; Logan \& Gordon, 2001) to provide principled measures of all of the processes involved.

\section{REFERENCES}

Awh, E., Jonides, J., \& Reuter-Lorenz, P. A. (1998). Rehearsal in spatial working memory. Journal of Experimental Psychology: Human Perception \& Performance, 24, 780-790.

Awh, E., \& PASHLER, H. (2000). Evidence for split attentional foci. Journal of Experimental Psychology: Human Perception \& Performance, 26, 834-846.

BUNDESEN, C. (1990). A theory of visual attention. Psychological Review, 97, 523-547.

Colegate, R. L., Hoffman, J. E., \& Eriksen, C. W. (1973). Selective encoding from multielement visual displays. Perception \& Psychophysics, 14, 217-224.

CowAn, N. (2001). The magical number 4 in short-term memory: A reconsideration of mental storage capacity. Behavioral \& Brain Sciences, 24, 87-185.

ERIKSEN, C. W., \& Collins, J. F. (1969). Temporal course of selective attention. Journal of Experimental Psychology, 80, 254-261.
Eriksen, C. W., \& Hoffman, J. E. (1972). Temporal and spatial characteristics of selective encoding from visual displays. Perception \& Psychophysics, 12, 201-204.

Kramer, A. F., \& Hahn, S. (1995). Splitting the beam: Distribution of attention over noncontiguous regions of the visual field. Psychological Science, 6, 381-386.

LoGAN, G. D. (2002). An instance theory of attention and memory. Psychological Review, 109, 376-400.

LoGAN, G. D., \& BundeSEN, C. (2003). Clever homunculus: Is there an endogenous act of control in the explicit task-cuing procedure? Journal of Experimental Psychology: Human Perception \& Performance, 29, 575-599.

LoGAN, G. D., \& Bundesen, C. (2004). Very clever homunculus: Compound stimulus strategies for the explicit task-cuing procedure. Psychonomic Bulletin \& Review, 11, 832-840.

LoGAN, G. D., \& GoRDON, R. D. (2001). Executive control of visual attention in dual-task situations. Psychological Review, 108, 393-434.

Mayr, U., \& Kliegl, R. (2003). Differential effects of cue changes and task changes on task-set selection costs. Journal of Experimental Psychology: Learning, Memory, \& Cognition, 29, 362-372.

Moore, C. M., Egeth, H., Berglan, L. R., \& LuCK, S. J. (1996). Are attentional dwell times inconsistent with serial visual search? $\underline{P s y-}$ chonomic Bulletin \& Review, 3, 360-365.

PYLYSHYN, Z. (1989). The role of location indices in spatial perception: A sketch of the FINST spatial-index model. Spatial Vision, 3, 179197.

SPerling, G., \& Weichselgartner, E. (1995). Episodic theory of the dynamics of spatial attention. Psychological Review, 102, 503-532.

TownsEnd, J. T. (1990). Serial vs. parallel processing: Sometimes they look like Tweedledum and Tweedledee but they can (and should) be distinguished. Psychological Science, 1, 46-54.

Treisman, A. (1982). Perceptual grouping and attention in visual search for features and objects. Journal of Experimental Psychology: Human Perception \& Performance, 8, 194-214.

TsAL, Y. (1983). Movements of attention across the visual field. Journal of Experimental Psychology: Human Perception \& Performance, 9,523-530.

WARD, R., DUNCAN, J., \& ShapIRo, K. (1996). The slow time-course of visual attention. Cognitive Psychology, 30, 79-109.

WoLFe, J. (1998). What can 1,000,000 trials tell us about visual search? Psychological Science, 9, 33-39.

\section{NOTE}

1. It is possible that attention is switched on all trials, but the switch is faster on same-cue and same-location trials than on other-location trials. To assess this possibility, I constructed a version of Model 1 in which attention was switched on every trial. I used Equation 2 for all conditions but allowed a different switching time $\left(\mu_{\mathrm{s}}\right)$ for same-cue and same-location trials than for other-location trials. The model fit the data well but required a 0 -msec cue encoding time to do so, which is unrealistic. When cue-encoding time was set equal to the estimates from the fits to Model 1, switching time for same-cue and same-location trials approached $0 \mathrm{msec}$, which is essentially Model 1.

(Manuscript received June 7, 2004; revision accepted for publication November 16, 2004.) 